available throughout the day and printed information should be provided. The disparity that we have shown should diminish as today's Asian teenagers progress through the British education system and acquire language fluency.

J CARNIE
B KUMAR

Department of Anaesthetics,

East Birmingham Hospital,

East Birmingham Ho Hirmingham B9 5ST
Bits

1 Bailey PW, Howard FA. Epidural analgesia and forceps delivery. Laying a bogey. Aneesthesia 1983;37:282-5.

potential for regional block. Anaesthesia 1982;37:
porial 784-8.

3 Holdcroft A, Morgan M. An assessment of analgesic effect in labour of pethidine and entonox. Fournal of Obstetrics and Gynaecology of the British Commonwealth $1974 ; 81$ :603-7.

SIR,-The paper by $\operatorname{Dr} R$ Balarajan and others ( 3 November, $p$ 1185) and the leading article by Dr John A Black (8 December, p 1558) were interesting. I would like to comment in the light of recent observations of the Glasgow Asian community.

Asian names are a useful proxy for ethnic origin, but intermarriage and change of name sometimes make Asians unidentifiable by this method, while other people may be wrongly identified as Asian. The method requires validation to quantify the likely error. In a recent study (in preparation) I found that three out of 100 names thought to be Asian were not so. Dr Balarajan and others go one step further by identifying region of origin and Moslem religion on the basis of name. Have they validated their technique, and what is the magnitude of error ? I accept that Moslem names are distinct. In my study I found that grouping into Moslem and non-Moslem categories on the basis of names was correct in $94 \%$ of cases. In view of major migrations, particularly in Northern India, and the derivation of large numbers of Asians from East Africa, it is unlikely that region of origin can be predicted with accuracy.

Dr Balarajan and others have failed to explain the astonishing male to female mortality ratio of $2.5: 1$ that occurs in every age group including children. The male to female ratio in the general population is about $0.94: 1 .^{1}$ A partial explanation may lie in sex differences in the number of Asians seeking health care in Britain (it is documented that more money is spent on the health care of males in India). Furthermore, women may be more likely to return to the Indian subcontinent when ill. My observations of Asian society support both hypotheses. Clearly, further study, including analysis of mortality data controlled for time spent in the host country, is necessary to explore this issue.

Dr Black identifies the communication gap as a major problem in the health care of Asians. Both language and differing concepts of the cause of disease and therapy are important. Of $18 \%$ of my study group who perceived a language problem, most felt that a family interpreter was sufficient. Illiteracy in English usually means the same in the native language. Leaflets produced in Asian languages would be useful for only $17 \%$ of my study group and $20 \%$ of a group in the West Midlands. ${ }^{2}$

I found that most Asians I interviewed were satisfied with the care they received within the NHS. It would be wise to introduce some of Dr Black's suggestions while this level of good will is high.

Despite speaking fluent Punjabi and being conversant with Hindi it took me $\mathbf{4 8}$ hours to understand the title of the leading article. May I suggest that "theek" may be better phonetic spelling than "thik."

R BHOPAI

Department of Community Medicine, Ruchill Hospital,
Glasgow G20 9 NB

1 Central Statistical Office. Social trends No 15. London: HMSO, 1985 .

2 Aslam M, Davis SS, Fletcher R. Compliance in medication by Asian immigrants. Nursing Times
1979;75:931-2.

\section{What can we do about measles?}

SIR,-We enjoyed Dr N D Noah's leading article on measles immunisation (1 December, $p$ 1476). After four years of practice in the United States we have yet to encounter a case of measles. This situation is in stark contrast to our experience in a population of similar size in Britain. The difference is undoubtedly due to the very high levels of immunisation achieved here. These levels are in turn due to immunisation being virtually compulsory in Kansas. Children are not admitted to school unless they have stringent proof of immunisation or certification that immunisation is contraindicated on medical or religious grounds. Children are required by law to attend school-catch 22 operates.

Anyone drawing unfavourable comparisons between immunisation coverage in Britain and that in the United States has to allow for the differences between the two societies. The immunisation requirement for school is, by and large, accepted as normal here and few "civil liberty" issues are raised. Retaining a voluntary basis for the immunisation programme may confer a moral advantage to the British system but it also carries an intrinsic disadvantage.

\section{University of Kansas,}

School of Medicine,

ADRIAN WALIING ANNE WALLING

\section{The rules of the game}

SIR,-Dr Theo Schofield, attempting to explain how he "leaked" the Wilkin and Metcalfe study on list size and patient contact in general medical practice ( 5 January, p 68), accused Doctor newspaper of "gross misrepresentation" and of being "inaccurate" in reporting the Wessex faculty of the Royal College of General Practitioners symposium.

Significantly this sweeping and disparaging statement was not substantiated by any specific reference to how we were inaccurate or misrepresentative. Indeed, this would have been impossible since our report was entirely accurate and fairly represented. Furthermore, our early review of the Wilkin and Metcalfe study was subsequently verified by the publication of the results of that study.

It is curious that, having noted the presence of our reporter, Dr Schofield should have been surprised to see his meeting reported in Doctor, but he is inaccurate in stating that our reporter did not speak directly to any of the speakers afterwards. She did, in fact, contact Dr Bill Styles about the study and also talked to one of its authors, who described the results as "political dynamite." Dramatic words, perhaps, but they were not of our coining.

Far more serious is the inference in $\mathrm{Dr}$ Schofield's letter that Doctor is not a reputable journal. As Doctor, like other newspapers, is a composite of many things, I wonder if he extends his aspersions to include the many distinguished members of the medical profession who regularly contribute to its columns.

Dr Schofield's "conclusion" that organisers of academic meetings should exclude reporters of medical newspapers is more pompous than sinister. But if academics are not prepared to tolerate others seeing issues in a slightly different light from the way they themselves view them it would be a sad day for freedom of expression in this or any other country.

I appreciate Dr Schofield's concern that he has unwittingly been caught up in this particular issue, but to seek to blame Doctor as a means of extricating himself is grossly unfair.

\section{Barrie Freeman}

Doctor, Guildford, Surrey GU1 3AD

\section{"Tissue thyrotoxicosis"}

SIR,-We have read with interest the report by Dr P E Jennings and others (15 December, $p$ 1645), which suggests that in patients receiving thyroxine replacement therapy for primary hypothyroidism a raised serum thyroxine concentration may indicate tissue thyrotoxicosis and should prompt a reduction in the thyroxine dose. This statement has enormous implications for the management of such patients, many of whom show serum total thyroxine and free thyroxine concentrations above the normal range while receiving standard replacement doses $(100-200 \mu \mathrm{g})$ of thyroxine without showing any clinical features of thyrotoxicosis. ${ }^{2}$

The findings of Dr Jennings and others should be interpreted with caution. They describe 15 subjects in whom the serum free thyroxine concentration was above normal and in whom there was a statistically significant reduction in mean systolic time interval ratio when compared with a group of 200 normal subjects. Of the 15 subjects described, only nine fell outside the stated normal range for systolic time interval ratio. It is not clear whether the study subjects were matched according to age, sex, and other criteria to the group of 200 normal subjects or whether conditions for measurement of the systolic time interval ratio were standardised, since changes in this value can be induced by such factors as age, sex, position, the time of day of the recording, drug therapy, and the presence of cardiovascular disease. ${ }^{3-5}$

When seven patients were reinvestigated one month after a $50 \mu \mathrm{g}$ reduction in thyroxine dosage there was a significant increase in mean systolic time interval ratio $(0.25$ to 0.28$)$. Five out of seven of the subjects retested were outside the stated normal range before dose reduction, but the authors do not make it clear how many of the subjects were within the normal range after reduction. In a similar study from the same group the normal range for the systolic time interval ratio was considered to be 0.25 to 0.32 , using the same method of measurement. 6 The mean systolic time interval ratio of the seven reinvestigated subjects would therefore have been considered normal had the range quoted by the authors been that in their previous report. It is said that all seven subjects reinvestigated were clinically euthyroid and symptom free after reduction of their thyroxine dosage, but presumably the subjects were clinically euthyroid and symptom free before reduction.

We do not think that the authors have shown adequately the presence of "tissue thyrotoxicosis as assessed by cardiovascular ... responses," nor is it 
justified to conclude that tissue thyrotoxicosis was indicated by the presence of a flat response of thyroid stimulating hormone to thyrotrophin releasing hormone in nine out of 11 subjects tested. Such a response may be evident in euthyroid subjects with ophthalmic Graves' disease or thyroid nodules, as well as for prolonged periods after the successful treatment of thyrotoxicosis. ? In addition, intracellular triiodothyronine within the pituitary is derived from both circulating triiodothyronine and from the local conversion of thyroxine to triiodothyronine. Intracellular triiodothyronine is derived from the deiodination of thyroxine to a larger extent in the pituitary than in any other tissue, ${ }^{8}$ and thus secretion of thyroid stimulating hormone is more closely related to circulating concentrations of thyroxine than any other biological response.

On the basis of the evidence presented a reduction in thyroxine dosage in all patients with a serum total or free thyroxine measurement above the normal range is not justified and may lead to unnecessary investigation and inadequate replacement in some patients with primary hypothyroidism. A reduction in thyroxine dose may be more sensibly confined to subjects in whom a high serum triiodothyronine is documented, in addition to high serum thyroxine, in the presence of clinical symptoms or signs of thyrotoxicosis.

\section{JANE A FrANKLY YN} M C SHEPPARD

Department of Medicine,

Queen Elizabeth Hospita

1 Ingbar JC, Borges M, Iflah S, et al. Elevated serum thyroxine concentration in patients receiving "replacement" doses

2 Pearce CJ, Himsworth RL. Total and free thyroid hormone concentrations in patients receiving maintenance replacement treatment with thyroxine. Br Med F 1984;288:693-5.

3 Weissler AM, Harris WS, Schoenfold CD. Bedside techniques for evaluation of ventricular function in man. Am f Cardiol 1969;23:577-83.

4 Lewis RP, Rittgers SE, Forester WF, et al. A critical review of sys

5 Chung $\mathrm{EK}$ Non-invasive cardiac diagnosis. London:

5 Chung EK. Non-invasive cardiac diagnosis. London:
Henry Kimpton, 1976 .
6 Northover B, O'Malley BP, Rosenthal FD. Alterations in systolic time intervals in primary hypothyroidism as a consequence of warming. $\mathcal{F}$ Clin Endocrinol Metab 1983;56:185-8.

7 Hall R, Anderson J, Smart GA, Besser M. Fundamentals of clinical endocrinology. Tunbridge Wells: Pitman Medical, 1980

8 Larsen PR, Silva JE, Kaplan MM. Relationships between circulating and intracellular thyroid hormones: physiological and clinical implications
Endocr $R e v 1981 ; 2: 87-102$.

SIR,-Dr P E Jennings and his coworkers (15 December, p 1645) state that 15 hypothyroid patients on replacement thyroxine $(100-200 \mu \mathrm{g}$ daily) with increased serum thyroxine concentrations were studied "to see whether the dose given was too high." Their statement that the systolic time intervals were in the thyrotoxic range is not true for six out of the 15 patients. Seven patients only out of the 15 were arbitrarily chosen to compare target cell measurementsthat is, systolic time intervals and thyrotrophin responsiveness before and after reduction of the thyroxine dose. Two out of the seven subjects had normal systolic time intervals and three did not have thyrotrophin responsiveness tested. The conclusion, based on the study. of the four remaining patients, appears to be that thyroxine replacement for hypothyroidism between 100 and $200 \mu \mathrm{g}$ daily is often too high, but in none of the four patients (cases 1, 7, 8, and 12) do they say what dose the patients were given.

P B S FOWLER

SIR,-The paper by Dr P E Jennings and others on the relevance of high serum thyroxine (T4) levels in patients receiving T4 replacement raises a number of interesting points. It is widely accepted that a good index of end organ response to thyroid hormones is needed, but we are surprised that the authors appear to have ignored both the systolic time interval and the response of thyroid stimulating hormone to thyrotrophin releasing hormone in the patients studied. We note that the dose of thyroxine was lowered in seven of the patients studied. Were the remaining four of the nine patients with a shortened systolic time interval, three of whom also had a flat response to thyrotrophin releasing hormone, considered to be euthyroid? If so, it would indicate that the systolic time interval is of no value in assessing thyroid status in these patients. We agree that high serum T4 concentrations may not be desirable in patients with "normal" triiodothyronine (T3) levels, but we were surprised at the thyroid stimulating hormone values that were found by the authors, as in our experience the thyroid stimulating hormone concentration is very rarely greater than $1 \mathrm{mU} / 1$ when the $\mathrm{T} 4$ is greater than 200 nmol/l.

We think that laboratories should establish reference ranges for thyroid function tests in patients receiving $\mathrm{T} 4$ replacement. These are likely to differ from the usual reference ranges because these take into account normal T3 secretion by the thyroid and because of the range of sensitivities in different tissues to $T 4$ and T3. ${ }^{1} \mathrm{We}$ are currently tackling this problem. Of 68 patients on T4 replacement, 47 were considered to be euthyroid by the examining physician and had a euthyroid score using a modified Wayne index. ${ }^{2}$ The thyroid function values of these 47 patients are given in the table. Twenty five patients

Thyroid function values in 47 patients taking thyroxine replacement and considered to be euthyroid

\begin{tabular}{|c|c|c|c|}
\hline & \multicolumn{2}{|c|}{$\begin{array}{l}\text { Euthyroid patients } \\
\text { on T4 replacement }\end{array}$} & \multirow{2}{*}{$\begin{array}{l}\text { Laboratory } \\
\text { reference } \\
\text { range }\end{array}$} \\
\hline & Mean (SD) & Range & \\
\hline Total T4 (nmol/l) & $135(29)$ & 74-198 & $55-144$ \\
\hline Free T4 $(\mathrm{pmol} / \mathrm{l})$ & $23(6)$ & $10-35$ & $9-25$ \\
\hline Total T3 $(\mathrm{nmol} / \mathrm{l})$ & $1.8(0.3)$ & $1 \cdot 0-2 \cdot 8$ & $0 \cdot 9-2 \cdot 8$ \\
\hline Free T3 $(\mathrm{pmol} / \mathrm{l})$ & $5.4(1.5)$ & $2 \cdot 3-10 \cdot 5$ & $2 \cdot 9-8 \cdot 9$ \\
\hline
\end{tabular}

had a total T4 greater than $144 \mathrm{nmol} / \mathrm{l}$ (the upper limit of the laboratory reference range). Fifteen of these were euthyroid and 10 were toxic by clinical diagnosis and Wayne index score. All 10 toxic patients had total T3 within the laboratory's reference range, and in only one was the free T3 raised. All 10 toxic patients had free T4 values above the laboratory's reference range, but in seven the free $\mathrm{T} 4$ value was within the range encountered in euthyroid patients on T4 replacement. Our experience would bear out the finding of $\mathrm{Dr}$ Jennings and his coworkers that measuring the serum T3 and free T3 is of little value in patients on T4 replacement. Our results to date indicate that there is little advantage in measuring free T4 over total T4 in these patients but suggest that the conventional reference range is not applicable in this group. This point is illustrated by Dr Jennings and others, who have shown that despite lowering the replacement dose the mean serum $\mathrm{T} 4$ and free T4 values were above their quoted "normal" range when the seven patients became euthyroid.

William D Fraser

D ST J O'REILLY

J A THOMSON

Departments of Medicine and Biochemistry, Royal Infirmary,

1 Larsen PR. Thyroid-pituitary interaction. N Engl I Med 1982;306:23-32.

Wayne EJ. Clinical and metabolic studies in thyroid disease. Br Med f 1960;i:1-11, 78-90.

\section{Fast neutron treatment for malignant} tumours of the facial area

SIR,-The important paper by Dr Mary Catterall and others (15 December, $p$ 1653) cannot be taken in isolation as a definitive description of treatment modalities for paranasal sinus cancer. The problem with this type of report is the way in which tumours with different biological properties are grouped together as if cancer was a single entity rather than a description of a group of diseases. Ten years after Conley and Dingman reported that adenoid cystic carcinoma has a five year survival of $74 \%$ and a 10 year survival of $28 \%$ we should not be reading that only one sixth of such tumours recurred, with no mention of length of follow up. Transitional cell carcinoma also has double the five year survival rate of squamous carcinoma. ${ }^{2}$

More specifically Dr Catterall and her colleagues tell us that the tumour regressed completely in 29 out of 31 patients and that the tumour was controlled in 25 out of 31 . But we are also told that seven died of metastasis and six of uncontrolled primary disease, leaving only 18 out of 31 . What do these terms response and control mean if the patients are dying of metastatic disease ?

The complications of treatment-in 10 patients-are severe but one could argue that with such advanced disease one has to pay a high price for treatment. However, the prospects of nationwide controlled trials, as suggested in the penultimate paragraph, are no nearer if the authors' use of patient numbers and lack of follow up detail are the corollary. Finally, not all operations on such patients take nine or 10 hours and require many different surgeons. There are many head and neck oncologists (usually ear, nose, and throat surgeons) who are capable of excision and reconstruction on their own.

A NARULA

O EL-SILIMY

P J BRADLEY

Department of Otolaryngology, Queen's Medical Centre,
Nottingham NG7 2UH 1 Conley J, Dingman DL. Adenoid cystic carcinoma

2 McNicoll W, Hopkin N, Dalley VM, Shaw HJ. Cancer of the paranasal sinuses and nasal cavities

SIR,-Without wishing to comment on the role of fast neutron therapy in the management of head and neck malignancies, I must nevertheless point out that any conclusions drawn by Dr Mary Catterall and others about the use of fast neutrons for malignant tumours of the facial area can only be very limited, given the facts in their paper. The most important point is that response to treatment is not synonymous with cure of disease, and it seems that 13 out of a total of 31 patients died of tumour, 